\title{
Inhibition of Stearoyl-CoA Desaturase 1 expression in human lung adenocarcinoma cells impairs tumorigenesis
}

\author{
NATALIA SCAGLIA ${ }^{1,2}$ and R. ARIEL IGAL ${ }^{2}$ \\ ${ }^{1}$ Instituto de Investigaciones Bioquímicas de La Plata (INIBIOLP), Facultad de Ciencias Médicas, \\ Universidad Nacional de La Plata, 1900 La Plata, Argentina; ${ }^{2}$ Department of Nutritional Sciences and Rutgers \\ Center for Lipid Research, Rutgers, The State University of New Jersey, New Brunswick, NJ 08901, USA
}

Received May 7, 2008; Accepted June 17, 2008

DOI: 10.3892/ijo_00000072

\begin{abstract}
Saturated (SFA) and monounsaturated (MUFA) fatty acids, the most abundant fatty acid species, have many divergent biological effects including the regulation of cell proliferation, programmed cell death and lipid-mediated cytotoxicity. Their distribution is regulated by Stearoyl-CoA Desaturases (SCD), the enzymes that convert SFA into MUFA. A positive correlation between high levels of tissue MUFA and several types of cancer has been reported, but a causal relationship between the function of SCD1, the main human SCD isoform, and cancer development has not yet been firmly established. Here we report that the stable knockdown of SCD1 gene expression in A549 human lung adenocarcinoma cells decreased the ratio MUFA/SFA in total lipids and inhibited the incorporation of glucose into cell lipids. Cell proliferation and anchorage-independent growth were considerably decreased in SCD1-depleted cells, whereas the rate of apoptosis was elevated, with respect to control A549 cells. In addition, phosphorylation of Akt-Ser473 and GSK-3ß-Ser9 was found notably impaired in SCD1-ablated A549 cells. Interestingly, the effects of SCD1 blockade on Akt activation, cancer cell growth and apoptosis could not be reversed by exogenously added oleic acid. Remarkably, the reduction of SCD1 expression in lung cancer cells significantly delayed the formation of tumors and reduced the growth rate of tumor xenografts in mice. Our study demonstrates that SCD1 activity regulates Akt activation and determines the rate
\end{abstract}

Correspondence to: Dr R. Ariel Igal, Department of Nutritional Sciences and Rutgers Center for Lipid Research, Rutgers, The State University of New Jersey, New Brunswick, NJ 08901, USA

E-mail: igal@aesop.rutgers.edu

Abbreviations: BSA, bovine serum albumin; FAS, fatty acid synthase; GSK-3ß, glycogen synthase kinase-3ß; MUFA, monounsaturated fatty acids; PBS, phosphate-buffered saline; PL, phospholipids; SCD, Stearoyl-CoA Desaturase; SFA, saturated fatty acids; TAG, triacylglycerol

Key words: monounsaturated fatty acid synthesis, human cancer cells, cell proliferation, tumor formation, Akt pathway of cell proliferation, survival and invasiveness in A549 cancer cells and shows, for the first time, that SCD1 is a key factor in the regulation of tumorigenesis in vivo.

\section{Introduction}

Lung cancer is the leading cause of cancer death in the US and one of the most deadly forms of cancer worldwide. The vast majority of lung cancer $(\sim 80 \%)$ belongs to the histopathological type of non-small cell lung cancer, with squamous cell carcinomas and adenocarcinomas as the most prominent forms (1). Since the 5-year survival rate of lung cancer remains disappointingly low $(\sim 14 \%)$, it is clear that a thorough understanding of the mechanisms of lung cancer development is necessary in order to discover new therapeutic targets. In this regard, lipid metabolism remains an under-studied area of cancer research, although information on lipid perturbations in cancer is mounting. For instance, a ubiquitous metabolic alteration in several types of cancer cells occurs in the de novo synthesis of fatty acids, the building blocks of cell membrane-forming phospholipids and storage lipids such as triacylglycerols and cholesteryl esters. While in normal cells fatty acid synthesis is inhibited by exogenous fatty acids uptaken from circulation, cancer cells display a high rate of fatty acid synthesis, propelled by excess substrates supplied by active glycolysis (2) and constitutively overexpressed fatty acid synthase (FAS) (3). Increased de novo fatty acid synthesis was shown in oncogene-transformed human cells (4) and in several types of cancer cells including breast and prostate cells (5-7). Importantly, the expression level of FAS has been correlated with poor cancer prognosis (3).

Notably, while two main products of de novo fatty acid synthesis and elongation, palmitic and stearic acids, are abundant in cancer cells, increased content of their monounsaturated fatty acid (MUFA) $\Delta 9$ desaturation products, palmitoleic and oleic acids, respectively, were also observed in transformed and cancer cells and tissues (8-10), suggesting that the high rate of fatty acid synthesis in cancer is coupled to the conversion of saturated fatty acids (SFA) into MUFA. High levels of expression and activity of Stearoyl-CoA Desaturase 1 (SCD1), the endoplasmic reticulum-resident $\Delta 9$ desaturase that converts SFA into MUFA (11), have been reported in several types of cancers, including colonic and 
esophageal carcinoma, hepatocellular adenoma, in mammary cancer cells as well as chemically induced tumors (12-15). However, high expression of SCD1 in human cancer tissues seems to be not universal. In histopathological studies of cancerous prostate epithelium, despite the presence of high levels of SREBP-1, a powerful activator of SCD1 gene transcription $(16,17)$, low levels of SCD1 have been reported (18).

In vitro studies have provided new evidence of a causal relationship between MUFA synthesis and several biological features of the cancer phenotype. We have reported that SV40-transformed human lung fibroblasts show significantly increased protein and activity levels of SCD1 with respect to their parental normal cell line (4), suggesting that a high rate of MUFA synthesis is needed for an active production of membrane lipids to sustain the fast replication rate of transformed cells (19). We have also shown that SV40transformed human lung fibroblasts bearing a knockdown of SCD1 exhibit a significant decrease in MUFA, cholesterol and phospholipid synthesis (20). Moreover, it was also found that SCD1 deficiency leads to a slower rate of cell proliferation, a loss of anchorage-independent growth and higher rates of ceramide-independent apoptosis, strongly indicating the participation of SCD1 in the regulation of cell proliferation, survival and invasiveness.

These observations in oncogene-transformed cells prompted us to determine whether a reduction of SCD1 expression and, consequently, in the synthesis and content of cellular MUFA would alter the in vitro and in vivo neoplastic phenotype of human lung cancer cells. Additionally, we wished to explore whether ablation of SCD1 expression in cancer cells would alter the activity of lipid-sensitive signaling pathways associated with cell growth, survival and cancer, such as the Akt pathway, hence causing the aforementioned phenotypical changes. Thus, in the present study, we examined the effect of the knockdown of SCD1 gene expression on cell growth, programmed cell death and the tumorigenic capacity of A549 cancer cells, a human lung adenocarcinoma cell line widely used as a good model for non-small cell lung cancer. The present results show that SCD1-deficient A549 cells exhibit slower in vitro cell proliferation, higher rates of apoptosis and impaired anchorage-independent colony formation. This loss of in vitro neoplastic phenotype was not reversed by exogenous oleic acid, suggesting that an endogenous pool of MUFA must be available for sustaining the biological alterations of lung cancer cells. Importantly, the reduction of SCD1 expression in A549 cells and in SV40-transformed cells promoted a decrease in the phosphorylation of both Akt and its downstream effector glycogen synthase kinase-3ß (GSK-3ß), suggesting that SCD1 may regulate cancer cell growth and survival by modulating the activity of the Akt signaling pathway. When A549 cells with ablated SCD1 expression were injected into mice, they exhibited not only a great delay in the formation of tumors, but also a slower rate of tumor growth. In summary, we report here that SCD1 appears to be an essential factor in the stepwise process leading to the onset and progression of lung cancer, laying the groundwork to explore the potential therapeutic applications of targeting SCD1 to treat human cancers.

\section{Materials and methods}

Materials. A549 human lung adenocarcinoma cancer cells were obtained from American Type Culture Collection (Rockville, MD). Four to six week-old female NIH Swiss nude $n u / n u$ mice were obtained from the Laboratory Animal Facility, University of La Plata School of Veterinary, Argentina. Standard rodent chow was purchased from Cargill-Grupo Pilar S.A, Argentina and sterilized by $\gamma$ radiation $(25 \mathrm{kGray})$ at IONICS, Buenos Aires, Argentina. Lipofectamine $^{\mathrm{TM}}$, pcDNA3 plasmid, Geneticin ${ }^{\mathrm{TM}}$, cell culture media and other culture reagents were from Invitrogen Life Technologies (Carlsbad, CA). Restriction enzymes and other molecular biology reagents were from Promega (Madison, WI). $\left[1-{ }^{14} \mathrm{C}\right]$ Stearic acid, $\left[{ }^{14} \mathrm{C}\right]$ glucose and $\left[6-{ }^{3} \mathrm{H}\right]-$ thymidine were from American Radiolabeled Chemicals, Inc. (St. Louis, MO). Ultrafiltered fetal bovine serum (FBS), fatty acid-free bovine serum albumin (BSA), mouse anti-ß-actin monoclonal antibody, anti-mouse IgG peroxidase conjugate, phosphatase and protease inhibitor cocktail were purchased from Sigma (St. Louis, MO). Pure lipid standards were from Doosan Serdary (Yongin, Korea). Palmitic and oleic acid were from NuCheck Prep (Elysian, MN). Cell culture supplies, silica gel 60 chromatography plates and analyticalgrade solvents were from Fisher Scientific (Morris Plains, NJ). Polyclonal anti-SCD1 antibody was a generous gift of Dr Jean-Baptiste Demoulin, Université Catholique de Louvain, Belgium. Polyclonal antibodies anti-total or phosphorylated Akt1/2/3 (Ser 473) and anti-pGSK-3ß (Ser 9) were from Santa Cruz Biotechnologies and Cell Signaling, respectively.

Cell culture. A549 cells were routinely cultured in bicarbonatebuffered minimum essential medium with Earle's salts (MEM) with $10 \%$ heat-inactivated FBS, penicillin (100 U/ml), streptomycin $(10 \mu \mathrm{g} / \mathrm{ml}), 1 \%$ non essential amino acids and $1 \%$ MEM vitamin solution (growing medium), at $37^{\circ} \mathrm{C}, 5 \%$ $\mathrm{CO}_{2}$ and $100 \%$ humidity.

Stable knockdown of SCD1 gene expression. The construct pcDNA3-hSCDas (for "human Stearoyl-CoA Desaturase antisense' cDNA) (20) was transfected into A549 cells using Lipofectamine reagent according to the manufacturers' instructions. Positively transfected cells were selected with $600 \mu \mathrm{g} / \mathrm{ml}$ Geneticin in a culture medium for 14 days. Individual cell colonies (hSCDas) were then isolated using cloning cylinders. One cell clone, hSCDas- $\alpha$, with low levels of SCD1 expression and activity was selected for performing the experiments. Empty pcDNA3 vector was stably transfected into A549 cells and these cells were considered the control cell line.

Immunoblotting. Western blot analysis was performed, as previously described (20). Polyclonal rabbit anti-human SCD1 (1:2000 dilution) or monoclonal mouse anti- $\beta$-actin (1:5000 dilution) were used as primary antibodies. Anti-total or phosphorylated Akt1/2/3 (Ser 473) and anti-pGSK-3ß (Ser 9) were used in a 1:250-1:1000 and 1:1000 dilutions, respectively. In some experiments, cells were cultured in $0.1 \%$ FBS for $24 \mathrm{~h}$ and incubated with $0.1 \mathrm{mM}$ of palmitic or oleic acid complexed with $0.5 \%$ fatty acid free BSA in $0.1 \%$ 
FBS supplemented media for 30 min before harvesting. The fatty acid concentration in media was determined with the NEFA C kit (Wako Chemicals, Richmond, VA).

Lipid extraction. Cell monolayers were washed twice with ice-cold PBS and scraped from the petri dishes with two additions of $1 \mathrm{ml}$ ice-cold methanol. One $\mathrm{ml}$ of chloroform and $0.5 \mathrm{ml}$ of distilled water were added in order to complete the extraction of total lipids, as described by Bligh and Dyer (21).

Determination of SCD activity. Preconfluent cells (80-90\% confluency) were incubated with trace amounts $(2.3 \mu \mathrm{M})$ of $\left[{ }^{14} \mathrm{C}\right]$ stearic acid $(0.25 \mu \mathrm{Ci} /$ dish $)$ in culture medium containing $0.5 \% \mathrm{BSA}$ for $6 \mathrm{~h}$. At the end of the incubation, total cell lipids were extracted as described. Total cellular lipids were saponified and released fatty acids were then esterified with $10 \% \mathrm{BF}_{3}$ in methanol for $3 \mathrm{~h}$ at $64^{\circ} \mathrm{C}$. The derivated methyl esters were separated by argentation thin layer chromatography (TLC) following the procedure of Wilson and Sargent (22), using a solvent phase consisting of hexane:ethyl ether (90:10, by vol). Pure stearic acid and oleic acid standards were run in parallel to the samples. Fatty acid spots on TLC were detected by radiometric scanning. Spots were scraped from the TLC plate and quantified with a scintillation counter. The level of $\left[{ }^{14} \mathrm{C}\right]$ oleic acid produced was calculated from specific activity of $\left[{ }^{14} \mathrm{C}\right]$ stearic acid and normalized to cellular protein content.

Metabolic labeling. Preconfluent cells were incubated for $6 \mathrm{~h}$ with $1 \mu \mathrm{Ci} /$ dish $\left[{ }^{14} \mathrm{C}\right]$ glucose, in $10 \%$ FBS MEM. At the end of the labeling period, the radioactive medium was recovered and cell monolayers were washed twice with $0.1 \%$ BSA in ice-cold phosphate-buffered saline (PBS), in order to eliminate residual label on the cell surface. Lipid extraction was carried out as described above.

Lipid analysis. Analysis of radioactivity of neutral and polar lipid species were carried out, as previously described (20). Briefly, neutral and polar lipid species were separated on silica gel 60 thin-layer chromatography (TLC) plates using one-dimensional single development procedures. Neutral lipid separation was carried out with hexane:ethylether:acetic acid, 80:20:2 (by vol) as solvent system. Pure lipid standards were seeded and run on the TLC plates in parallel to samples. Individual $\left[{ }^{14} \mathrm{C}\right]$ labeled lipid-spots detected by radiometric scanning were scraped into plastic vials and radioactivity levels were determined in a liquid scintillation counter. The amount of $\left[{ }^{14} \mathrm{C}\right]$ tracer incorporated in each lipid class was calculated from the specific activity of each substrate and normalized to cellular protein content. For the analysis of fatty acid composition, methyl esters of fatty acids were obtained as described above and analyzed by gas chromatography in a Hewlett Packard HP6890 GC apparatus, fitted with a flame ionization detector and equipped with an OmegaWax 250 capillary column. Chromatographic peaks were identified by comparison of their retention times with those of pure fatty acid standards and percent distribution was calculated.

Cell proliferation. To determine the growth rate of control and hSCDas- $\alpha$ cell lines, $1.6 \times 10^{5}$ cells were seeded in triplicate $60-\mathrm{mm}$ petri dishes. Twenty-four hours later, medium was replaced with fresh medium. The medium was then changed every two days. At different time points up to $144 \mathrm{~h}$, cells were trypsinized and counted in an hemocytometer. At all time points, cell viability, as determined by the trypan blue exclusion test, was $95 \%$ or higher.

$\left[{ }^{3} H\right]$ Thymidine incorporation into cell DNA. The rate of DNA synthesis of hSCDas- $\alpha$ and control cells was estimated by determining the levels of $\left[{ }^{3} \mathrm{H}\right]$ thymidine incorporation into DNA after pulsing the cells with the radiolabeled tracer for $2 \mathrm{~h}$, followed by precipitation of total DNA and scintillation counting, as described by Bagnato and Igal (19). Groups of cells were incubated with $200 \mu \mathrm{M}$ oleate for $48 \mathrm{~h}$ previous to $\left[{ }^{3} \mathrm{H}\right]$ thymidine labeling.

Colony formation assay. Control and hSCDas- $\alpha$ cells were plated at $1 \times 10^{4}$ cells per $60-\mathrm{mm}$ dishes in quadruplicate in MEM containing $10 \% \mathrm{FBS}$, in the presence or absence of $200 \mu \mathrm{M}$ oleate and $0.3 \%(\mathrm{w} / \mathrm{v})$ agar plated onto a bottom layer of $0.6 \%(\mathrm{w} / \mathrm{v})$ agar in MEM. After 4 weeks, cell colonies were stained with ethidium bromide in PBS for $2 \mathrm{~h}$ and photographed under UV light. Colonies were counted using a Molecular Imager ChemiDoc XRS system (Bio-Rad Laboratories, Hercules, CA).

Apoptosis analysis: fragmentation of $\left[{ }^{3} \mathrm{H}\right]$ thymidine-labeled $D N A$. The determination of DNA fragmentation was performed essentially as described by Venable et al (23). DNA samples from preconfluent hSCDas- $\alpha$ cells and control cells were labeled with $0.4 \mu \mathrm{Ci}\left[{ }^{3} \mathrm{H}\right]$ thymidine in a regular growing medium for $24 \mathrm{~h}$. The medium was removed, the cell monolayers were washed twice with PBS at $37^{\circ} \mathrm{C}$ and cells were allowed to grow for $24 \mathrm{~h}$. Then, the chase medium containing detached apoptotic cells was collected and the $\left[{ }^{3} \mathrm{H}\right]$ radioactivity was determined in a scintillation counter. Cell monolayers were lysed in PBS with $1 \%$ Triton X-100 and $0.2 \mu \mathrm{M}$ EDTA, collected and sedimented by centrifugation at $14,000 \mathrm{rpm}$ for $15 \mathrm{~min}$. Radioactivity was quantified in the supernatant, containing fragmented $\left[{ }^{3} \mathrm{H}\right] \mathrm{DNA}$ and in the pellet containing the intact cellular DNA, which was washed and resuspended in $1 \%$ Triton $\mathrm{X}-100$ and $0.2 \mu \mathrm{M}$ EDTA. The levels of fragmented DNA was estimated according to the following calculation: (chase medium DPM + supernatant DPM)/total DPM.

Analysis of tumor formation. Four to six-week-old female Swiss nude mice were maintained in isolators under pathogenfree conditions and kept in a $12 \mathrm{~h} / 12 \mathrm{~h}$ light/dark cycle. After a 15-day acclimatization period, mice were subcutaneously inoculated in the interscapular space with $1 \times 10^{6} \mathrm{hSCD} a s-\alpha$ or control A549 cells resuspended in $0.1 \mathrm{ml}$ PBS. Two independent experiments were performed with five animals per group and per experiment. The time of appearance of local tumors was monitored by palpation. Tumor size was measured weekly using caliper and tumor volume were calculated by the equation $a^{2} \times b / 2$, where $a$ is tumor width and $b$ is tumor height. Data are presented as mean relative tumor volume where initial tumor volume is 1 . After six weeks from tumor appearance, mice were euthanized and tumors were excised for further studies not reported here. Experimental protocols in 
A

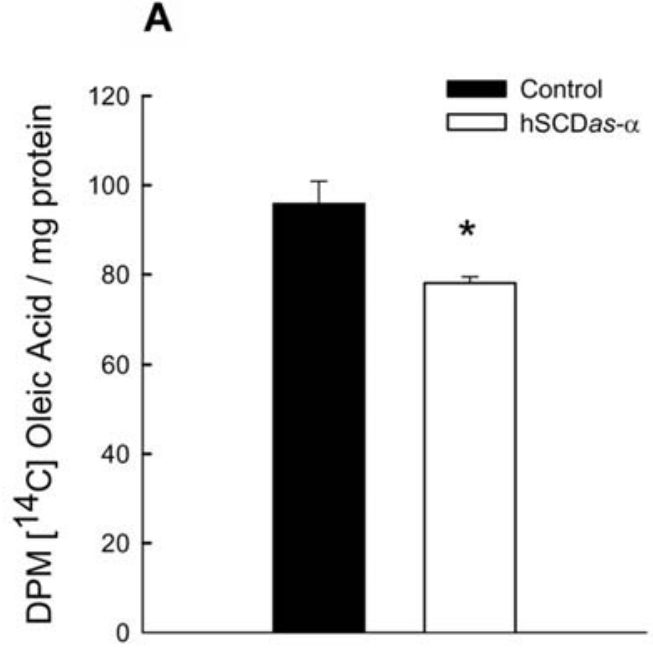

B

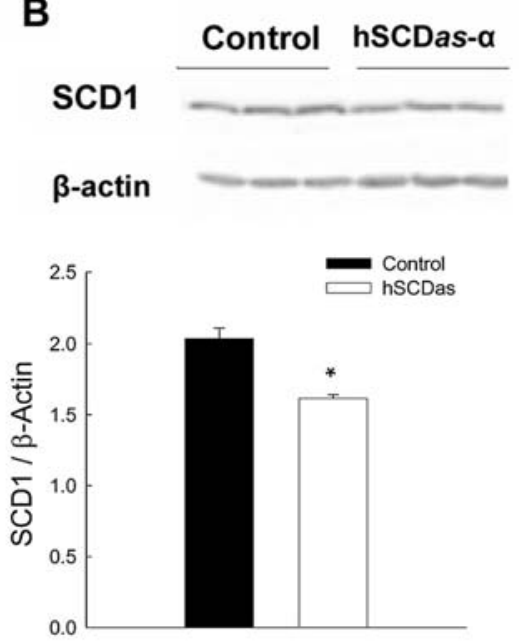

Figure 1. Reduced SCD activity and protein levels in hSCDas- $\alpha$ cells. $\Delta 9$-desaturating activity (A) was determined in the control and hSCDas- $\alpha$ cells by incubating near confluent cell monolayers with $\left[{ }^{14} \mathrm{C}\right]$ stearic acid $(0.25 \mu \mathrm{Ci} /$ dish $)$ for $6 \mathrm{~h}$ in $10 \% \mathrm{FBS}$, MEM. The levels of SCD product, $\left[{ }^{14} \mathrm{C}\right]$ oleic acid, were determined after separation of fatty acids on silver nitrate-impregnated TLC plates and radioactivity counting. Values represent the mean \pm SD of triplicate determinations. ${ }^{*} \mathrm{P}<0.01$, by Student's t-test. For Western blot analysis of SCD1 (B), homogenates of preconfluent control and hSCDas- $\alpha$ cells were prepared by sonication on ice. Total cellular proteins were separated by SDS-PAGE and levels of SCD1 and B-actin were determined by Western blotting and densitometric analysis.

animals were performed according to the Animal Welfare Guidelines of NIH (INIBIOLP's Animal Welfare Assurance No. A5647-01).

Determination of cellular protein. Total cellular protein content was measured by Bradford method (Pierce), using BSA as a standard.

Statistical analysis. Results from a representative experiment with 3-5 samples per experimental group are presented as means \pm SD. Statistical significance of the data was determined by Student's t-test or one-way ANOVA followed by the Bonferroni test.

\section{Results}

Stable ablation of SCD1 expression reduces MUFA and increases SFA in total cell lipids. Previously, we reported that the knockdown of SCD1 gene expression in SV40-transformed human lung fibroblasts led to either reduction or suppression of several parameters of neoplastic behavior in vitro (20). In order to test whether ablation of SCD1 expression in human cancer cells may affect in vivo tumor formation, we generated a model of SCD1 depletion in A549 human lung adenocarcinoma cells. To do so, A549 cells were stably transfected with a plasmid containing a fragment of human SCD1 cDNA in an antisense orientation (hSCDas cells) or with the empty vector (control cells). After clonal selection, SCD activity and protein levels were estimated in SCDas cell colonies. In one selected colony (hSCDas- $\alpha$ ), SCD activity was significantly diminished ( 20\%) with respect to mock-transfected A549 cells (control) (Fig. 1A). The reduction in SCD activity was caused by lower levels of SCD1 protein (Fig. 1B). The observation that stable knockdown of SCD1 expression was unable to produce cell colonies with an inhibition of SCD1 expression and activity $>20 \%$ in cancer cells is puzzling and may indicate that, due to selection pressure, cells with more
Table I. Fatty acid composition of total lipids from hSCDas- $\alpha$ and control cells. ${ }^{\mathrm{a}}$

\begin{tabular}{lcc}
\hline Fatty acid (\%) & Control & hSCD $a s-\alpha$ \\
\hline $14: 0$ & $2.24 \pm 0.20$ & $3.82 \pm 0.94^{\mathrm{d}}$ \\
$16: 0$ & $24.33 \pm 0.57$ & $29.17 \pm 2.33^{\mathrm{c}}$ \\
$16: 1 \mathrm{n}-7$ & $14.53 \pm 0.40$ & $11.23 \pm 0.70^{\mathrm{b}}$ \\
$18: 0$ & $12.02 \pm 0.38$ & $13.28 \pm 1.10$ \\
$18: 1 \mathrm{n}-9$ & $32.61 \pm 0.76$ & $27.15 \pm 1.86^{\mathrm{c}}$ \\
$18: 1 \mathrm{n}-7$ & $7.78 \pm 0.81$ & $7.99 \pm 0.15$ \\
$18: 2 \mathrm{n}-6$ & $2.62 \pm 0.08$ & $2.53 \pm 0.48$ \\
$20: 4 \mathrm{n}-6$ & $3.86 \pm 0.23$ & $4.82 \pm 0.45^{\mathrm{c}}$ \\
$16: 1 \mathrm{n}-7 / 16: 0$ & $060 \pm 0.01$ & $0.39 \pm 0.01^{\mathrm{b}}$ \\
$16: 1 \mathrm{n}-7+18: 1 \mathrm{n}-7 / 16: 0$ & $0.92 \pm 0.04$ & $0.66 \pm 0.03^{\mathrm{b}}$ \\
$18: 1 / 7-9 / 18: 0$ & $2.71 \pm 0.06$ & $2.05 \pm 0.03^{\mathrm{b}}$ \\
MUFA/SFA & $1.42 \pm 0.02$ & $1.00 \pm 0.07^{\mathrm{b}}$ \\
\hline
\end{tabular}

aTotal cellular lipids were extracted from SCD1-depleted A549 cells and controls and their fatty acids were converted into methyl esters and analyzed by capillary gas chromatography. Results are expressed as percent distribution of fatty acids and correspond to the mean $\pm \mathrm{SD}$ of four samples. ${ }^{\mathrm{b}} \mathrm{P}<0.001 ;{ }^{\mathrm{c}} \mathrm{P}<0.01 ;{ }^{\mathrm{d}} \mathrm{P}<0.05$, by the Student's t-test.

reduced SCD1 expression may not be viable. Nevertheless, as described below, this modest degree of SCD1 inhibition was sufficient for promoting significant changes in the biochemical and biological phenotype of cancer cells.

As a result of SCD1 reduction, the distribution of fatty acid species in total cellular lipids of SCD1-ablated cells was considerably altered (Table I). The main products of SCD activity, palmitoleic and oleic acids, were diminished by 23 and $17 \%$, respectively, in hSCDas- $\alpha$ cells compared to controls. 


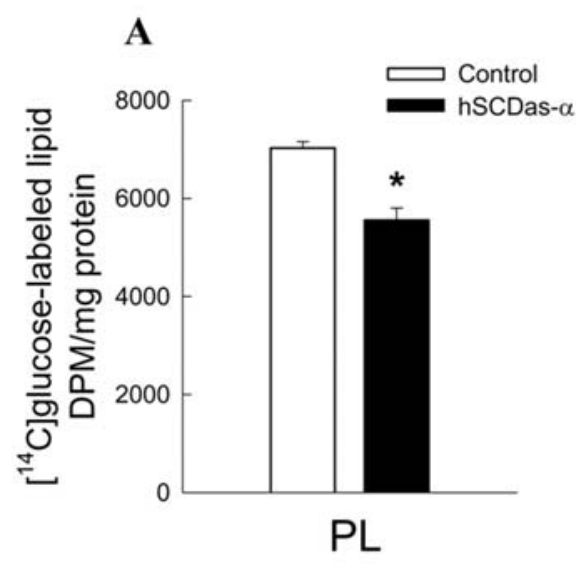

B

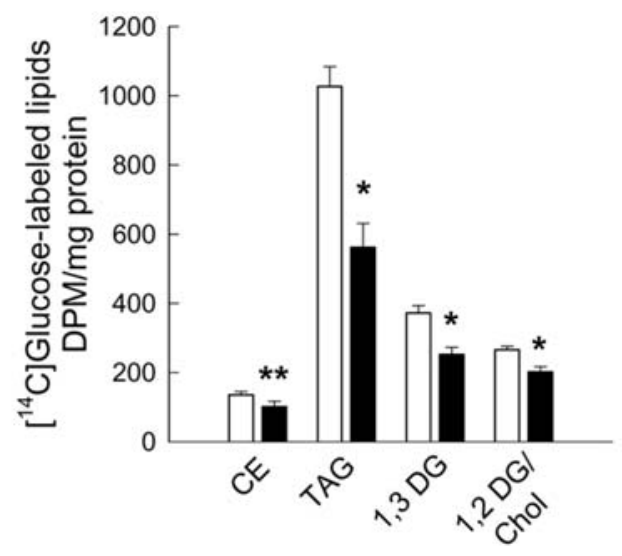

Figure 2. Inhibition of SCD1 expression impairs glucose-derived lipogenesis. The rate of lipogenesis was measured in mock-transfected and SCD1-deficient A549 cells by labeling the lipids with $\left[{ }^{14} \mathrm{C}\right]$ glucose $(1 \mu \mathrm{Ci} /$ petri dish $)$ for $6 \mathrm{~h}$. Total cell lipids were extracted and $\left[{ }^{14} \mathrm{C}\right]$ lipid fractions were detected and quantified by TLC and radioactivity counting. PL, phospholipids; TAG, triacylglycerols; DAG, diacylglycerol; Chol, free cholesterol; FFA, free fatty acids and CE, cholesterylesters. Data are represented as means $\pm \mathrm{SD}, \mathrm{n}=3$, ${ }^{* *} \mathrm{p}<0.05 ;{ }^{*} \mathrm{p}<0.01$, compared to control cells.

In addition, the most abundant SFA, palmitic acid, was increased by $20 \%$ in the cells deficient in SCD1 with respect to mock-transfected cells. Consequently, the MUFA to SFA ratio in total lipids of hSCDas- $\alpha$ decreased by $\sim 30 \%$. Increases in myristic acid (70\%) and arachidonic acid (25\%) were also observed in SCD1-deficient A549 cells. These results clearly indicate that the total fatty acyl chain composition of lipids in A549 cells is determined by SCD1 activity, even when these cells were grown in FBSsupplemented medium containing MUFA.

Reduction of SCD1 expression impairs the formation of lipids from glucose in cancer cells. Cancer cells make preferential use of glucose as a nutrient in order to satisfy the demands of both metabolic energy through aerobic glycolysis and substrates for the biosynthesis of macromolecules such as DNA, proteins and lipids (24). Importantly, glycolysis also provides metabolites such as citrate and glycerol that will be used for the de novo synthesis of cellular lipids. We have previously reported that oncogene-transformed cells with reduced levels of SCD1 exhibited an impaired lipogenesis (16). We reasoned that glucose-mediated formation of lipids could be a metabolic target for SCD1 in cancer cells. Thus, cells were traced with $\left[{ }^{14} \mathrm{C}\right]$ glucose and the formation of $\left[{ }^{14} \mathrm{C}\right]$ lipids was determined. $\left[{ }^{14} \mathrm{C}\right]$ glucose was predominantly incorporated into the phospholipid pool of both A549 cell groups (Fig. 2A and B), indicating that the main metabolic fate of de novo synthesized lipid substrates is the formation of new membrane lipids. The synthesis of phospholipids from glucose was significantly decreased in A549 cells with a knockdown in SCD1 with respect to controls (Fig. 2A), suggesting that SCD1 modulates the use of glucose-derived metabolites for the production of membrane-forming lipids in cancer cells. The observation that the inhibition of SCD1 also reduced the formation of energy storing lipids such as TAG and CE (Fig. 2B) further confirms the regulatory effect of SCD1 on the overall process of de novo lipid synthesis in neoplastic cells.

Alterations in proliferation, programmed cell death and anchorage-independent growth in SCD1-deficient A549 cells. Inhibition of SCD1 gene expression in SV40-transformed human lung fibroblasts reduces cell growth by decreasing cell proliferation and increasing programmed cell death (20). Hence, we asked whether human tumor-derived cells would be equally sensitive to SCD1 depletion with respect to cell replication and programmed cell death. As shown in Fig. 3A, mock-transfected control cells rapidly replicated during the course of the experiment whereas hSCDas- $\alpha$ cells proliferated at a considerably reduced rate, with increasing differences from control cells over time. In order to confirm the antiproliferative effect of SCD1 inhibition, we determined the rate of DNA synthesis using $\left[{ }^{3} \mathrm{H}\right]$ thymidine as a tracer. The levels of [ $\left.{ }^{3} \mathrm{H}\right] \mathrm{DNA}$ formation were reduced in SCD1-depleted cells by $\sim 35 \%$ with respect to controls (Fig. 3B). Since it has been reported that exogenous oleic acid increases proliferation in cancer cells (26), the synthesis of DNA in cells supplemented with $200 \mu \mathrm{M}$ oleate was analyzed. Notably, while exogenous oleate significantly increased the incorporation of $\left[{ }^{3} \mathrm{H}\right]$ thymidine into newly synthesized DNA in the mocktransfected A549 cells, the depressed DNA synthesis in SCD1-ablated cells was not reversed by oleate treatment (Fig. 3B), indicating that an active endogenous MUFA synthesis is specifically required to sustain proliferation in the lung cancer cells.

We and others have reported that SCD1 prevents programmed cell death and lipid mediated cytotoxicity in mammalian and human cells $(20,26)$. Therefore, we assessed the rate of apoptosis in A549 cells with stably reduced levels of SCD1. We observed that the levels of fragmentation of DNA, a measure of apoptotic damage, was increased by $\sim 40 \%$ in hSCDas- $\alpha$ cells with respect to their control counterparts (Fig. 3C), further supporting a role of SCD1 in preventing programmed cell death in neoplastic cells.

The above described modifications in proliferation and death rates of A549 cells with reduced SCD1 expression led to a significant reduction in overall cellular growth. The population doubling time increased an average of $25 \%$ in hSCD as $-\alpha$ cells compared to mock-transfected controls. Moreover, the saturation density, another phenotypic feature typically altered in neoplastic cells, was $\sim 40 \%$ lower in SCD1-ablated cells (data not shown). Taken together, these 


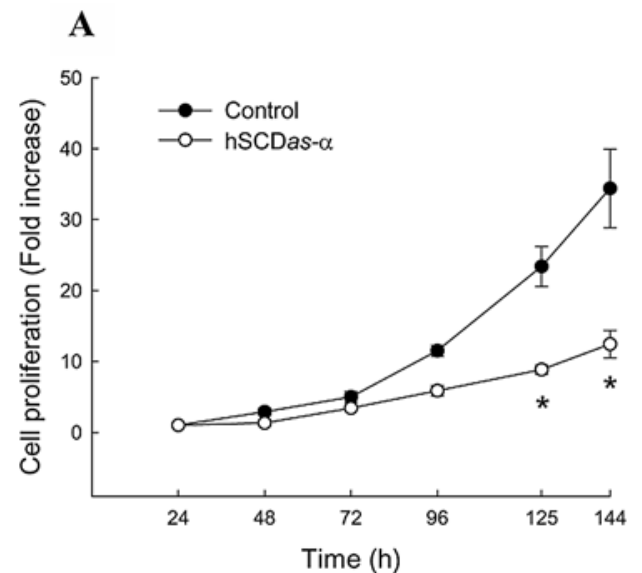

B

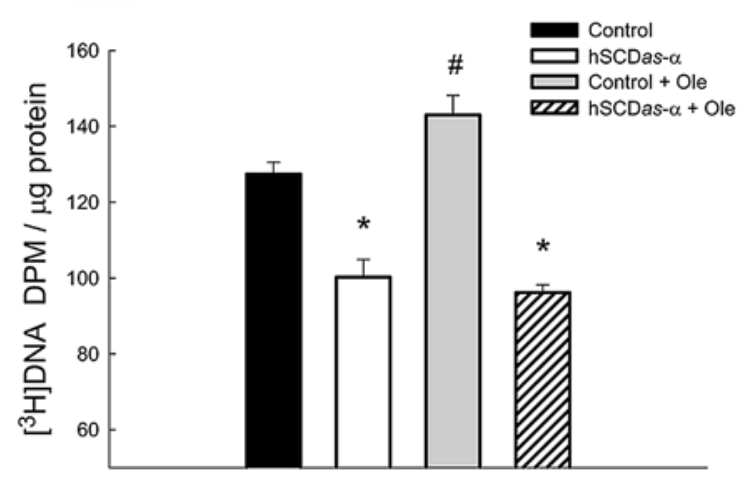

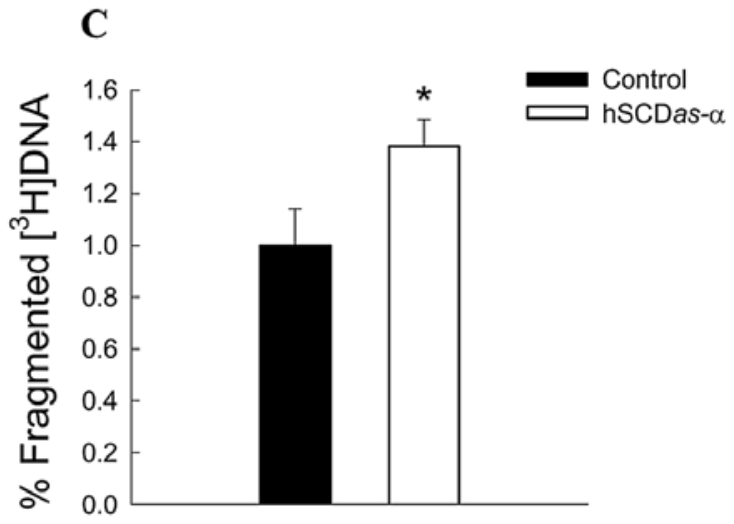

D

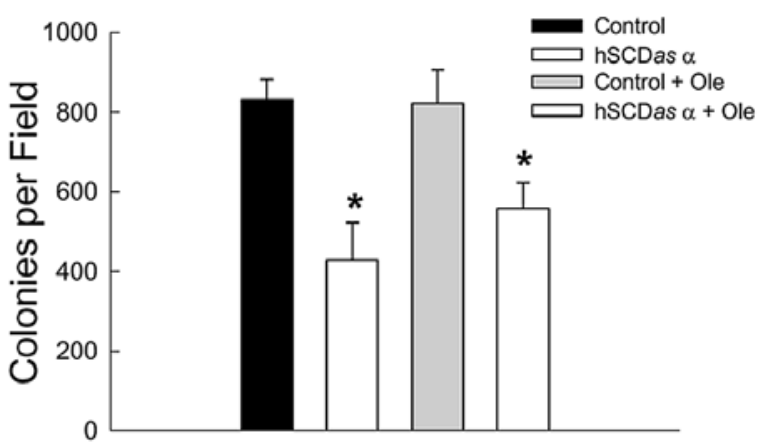

Figure 3. Ablation of SCD1 gene expression reduces cell proliferation and anchorage-independent growth and increases programmed cell death. (A) Control and hSCD as - $\alpha$ cells were seeded in 60-mm petri dishes and grown for up to $144 \mathrm{~h}$ in MEM plus $10 \%$ FBS. At different time points, cells were trypsinized and counted in a hemocytometer. Data represent triplicate dishes. ${ }^{*} \mathrm{P}<0.001$, by Student's t-test. (B) Preconfluent mock-transfected control and hSCDas- $\alpha$ cells were pulsed with $\left[{ }^{3} \mathrm{H}\right]$ thymidine $(1 \mu \mathrm{Ci} /$ dish $)$ in $10 \% \mathrm{FBS}$, MEM for $2 \mathrm{~h}$ and $37^{\circ} \mathrm{C}$. Total $\left[{ }^{3} \mathrm{H}\right]$-labeled DNA was precipitated and radioactivity was quantified in a scintillation counter. Groups of cells were incubated with $200 \mu \mathrm{M}$ oleate for $48 \mathrm{~h}$ previous to $\left.{ }^{3} \mathrm{H}\right]$ thymidine labeling. Values correspond to the mean $\pm \mathrm{SD}$ of quadruplicate dishes. Bars bearing different symbols are significantly different at $\mathrm{p}<0.001$, ANOVA. (C) Programmed cell death was estimated by fragmentation of $\left[{ }^{3} \mathrm{H}\right]$ thymidine-labeled DNA in control and hSCDas- $\alpha$ cells grown in MEM plus $10 \%$ FBS. Bars represent the means \pm SD of quadruplicate samples. ${ }^{*}<0.01$ by Student's t-test. (D) A549 cells (1.0x104) bearing an SCD1 gene knockdown and corresponding controls, were seeded in 60 -mm dishes containing 10\% FBS MEM and $0.3 \%$ agar, with or without $200 \mu \mathrm{M}$ oleate, over a layer of $0.6 \%$ agar. After 4 weeks, multicellular colonies were stained with ethidium bromide and photographed under UV light. Colonies were counted on several macroscopic fields of each petri dish using a Molecular Imager Chemidoc XRS. Values represent the mean \pm SD of triplicate samples. Bars with different symbols are significantly different at p<0.05 (ANOVA).

observations argue for a relevant role of SCD1 in the regulation of growth and survival of lung cancer cells.

To further explore whether the alterations in cell growth and apoptosis in SCD1-ablated A549 cells were accompanied by other changes in the malignant phenotype, we tested the effects of SCD1 knockdown on anchorage-independent growth. In order to allow the development of multicellular colonies, cells were grown in soft agar for up to 4 weeks. As shown in Fig. 3D, control cells were able to produce multiple cell colonies whereas hSCDas- $\alpha$ cells showed a considerably diminished number of colonies, suggesting that high levels of SCD1 are needed to develop a full anchorage-independent growth capacity. Moreover, MUFA synthesized by SCD1 appear to be essential lipids for sustaining this phenotypical feature, because the addition of oleic acid to the growth medium failed to reverse the low capability of SCD1-deficient cells to form multicellular colonies in soft agar (Fig. 3D).

The Akt pathway is downregulated in lung cancer cells with reduced expression of SCD1. Akt, or protein kinases $\mathrm{B}(\mathrm{PKB})$, is a family of serine/threonine kinases that has been implicated in several aspects of cancer development, including cell proliferation, apoptosis and metabolic changes associated with neoplasia such as increased aerobic glycolysis and lipogenesis $(6,27,28)$. Among other factors, the Akt pathway is regulated by fatty acids. Exogenously added oleic acid, the main product of SCD1 activity, has been shown to promote cellular proliferation and survival through PI3K/Akt activation in breast cancer cells, whereas palmitic acid, the main SFA in mammalian cells, has opposite effects (29). We hypothesized that the imbalance in SFA and MUFA content promoted by blockade of SCD1 expression in lung cancer cells would affect the level of phosphorylated (active) Akt. As shown in Fig. 4A, SCD1-deficient cells exhibited a decrease of $\sim 40 \%$ in the ratio p-Akt to total Akt compared with mock-transfected control cells. We also observed a $70 \%$ decrease in p-Akt/total Akt in SV40-transformed human lung fibroblasts with stably reduced levels of SCD1 expression with respect to the control cell line (Fig. 4B), suggesting that the regulation of Akt activation is not cell-type specific. Several biological responses to Akt activation are mediated by the inactivation of glycogen synthase kinase-3ß (GSK-3ß), which is phosphorylated at 


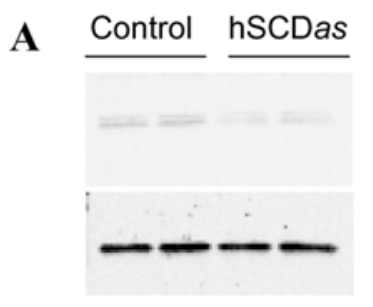

pAkt (Ser 473)

Total Akt

B

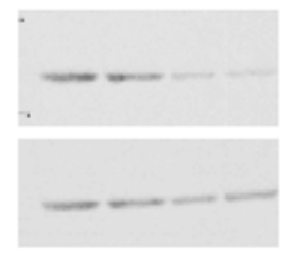

pAkt (Ser 473)

Total Akt

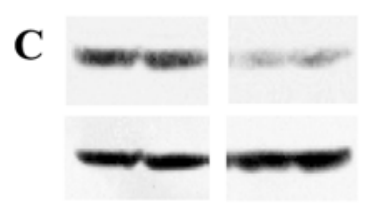

pGSK-3 $\beta$ (Ser 9)

$\beta$-Actin
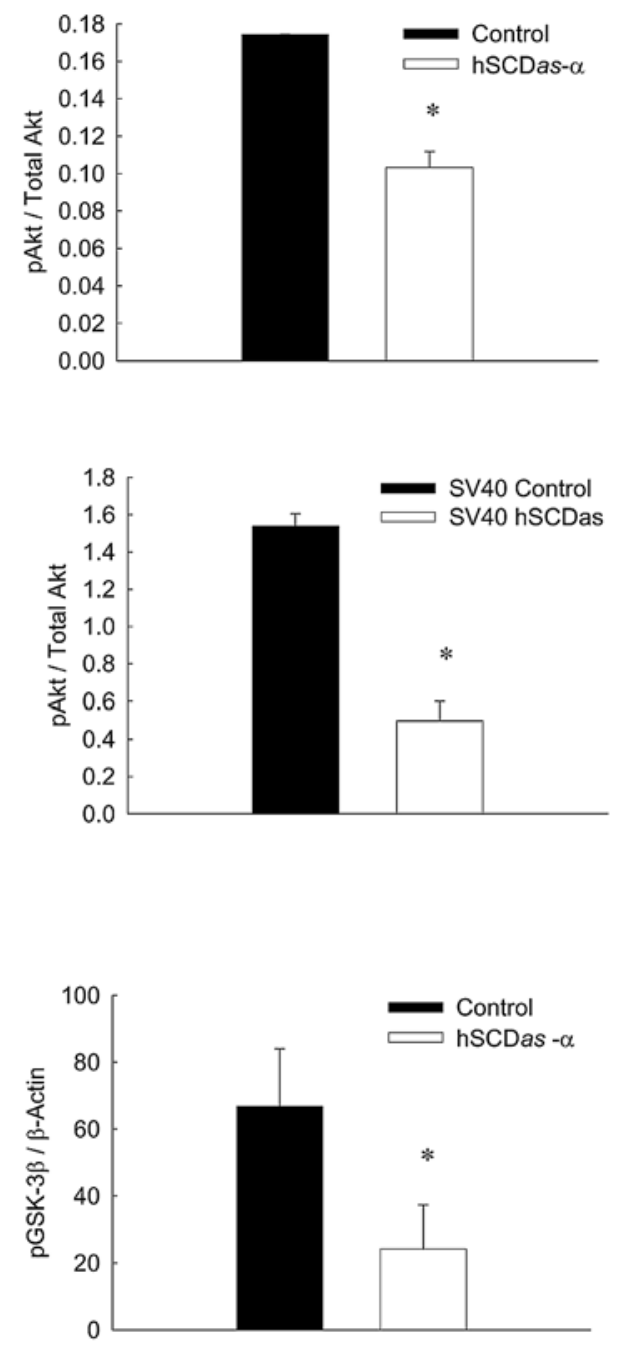

Figure 4. SCD1 knockdown decreases Akt and GSK-3ß phosphorylation. Homogenates of preconfluent control and hSCDas cells were prepared. Total cellular proteins were separated by SDS-PAGE and levels of pAkt (Ser 473) and total Akt (A and B), pGSK-3ß (Ser 9) and ß-actin (C) were determined by Western blotting and densitometric analysis in A549 cells (A and C) or in SV40-transformed human lung fibroblasts (B). Data correspond to the mean \pm SD in triplicate samples. $\mathrm{P}<0.05$, by Student's t-test.

Ser9 by Akt (30,31). Therefore, we estimated the level of phosphorylated GSK-3ß in hSCDas- $\alpha$ cells as well as in their respective controls. As shown in Fig. 4C, phosphorylation of GSK-3ß was significantly decreased in the SCD1-deficient cells compared to controls, further supporting the role of SCD1 in the regulation of the Akt activity in neoplastic cells.

To test the effect of exogenous fatty acids on Akt activation, control and SCD1-depleted A549 cells were grown for $24 \mathrm{~h}$ in $0.1 \% \mathrm{FBS}$ and then stimulated for $30 \mathrm{~min}$ with $0.1 \mathrm{mM}$ palmitic or oleic acid bound to $0.5 \% \mathrm{BSA}$ in FBS depleted media as described in Materials and methods. These conditions have been shown to be the most effective for fatty acid-induced activation of Akt in cancer cells (25). After the incubation with $0.1 \%$ FBS, the reduction in Akt phosphorylation observed in hSCDas cells with respect to control cells remained unchanged (Fig. 5). Moreover, the reduction in Akt phosphorylation persisted when the cells were incubated for 30 min with $10 \%$ FBS after 24 h of serum depletion (data not shown). Treatment with palmitic acid did not affect Akt phosphorylation in either A549 cell groups compared to BSA treatment (Fig. 5). Interestingly, exogenous oleic acid induced Akt activation in control cells but not in SCD1-deficient cells, suggesting that SCD1 activity is required for fatty acidmediated Akt activation.

Reduced tumorigenesis in mice injected with SCD1-depleted A549 cells. Since the knockdown of SCD1 gene expression considerably impaired the in vitro neoplastic behavior of A549 cells, we investigated whether a reduction of SCD1 levels would compromise the ability of these lung cancer cells to develop tumors in mice. Hence, SCD1-deficient and control A549 cells were injected subcutaneously into athymic nude mice and tumor growth was determined for up to 150 days. We observed a remarkable increase in tumor latency in tumors originating from A549 cells with the knockdown of SCD1 expression with respect to those derived from mock-transfected A549 (Fig. 6A). In two independent experiments, control A549 cells formed tumors in $100 \%$ of the mice within two weeks after cell inoculation, whereas cells with reduced SCD1 levels produced measurable tumors after $\sim 80$ days postinjection. Strikingly, only $40 \%$ of hSCDas- $\alpha$ cells produced measurable tumors after 60 days (experiment 1 ) and 80 days (experiment 2), respectively (Fig. 6A, inset), indicating that the ablation of SCD1 activity significantly delays the formation 
A

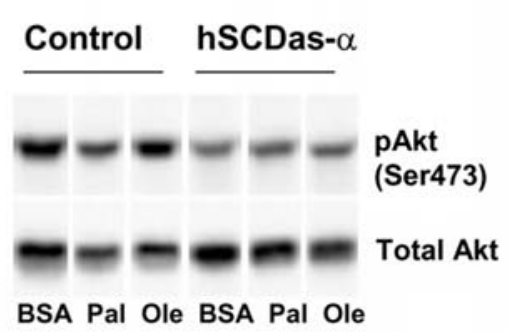

B

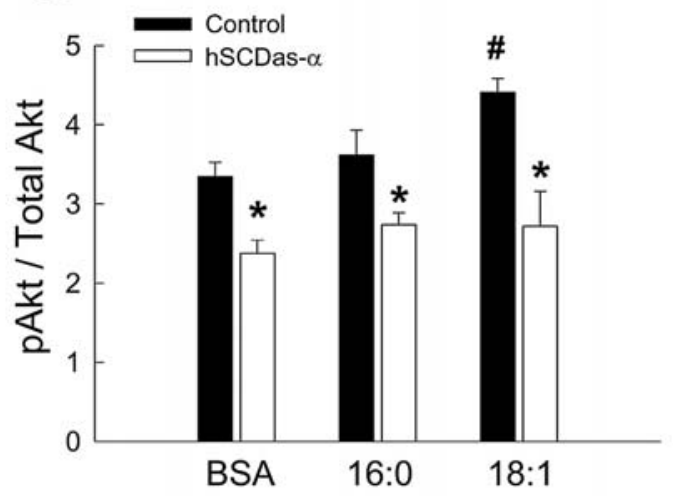

Figure 5. Exogenous oleic acid does not reverse the reduced Akt phosphorylation in SCD1-deficient A549 cells. Preconfluent A549 cells were grown in 0.1\% FBS supplemented media for $24 \mathrm{~h}$ and then treated with $0.1 \mathrm{mM}$ palmitic (Pal) or oleic acid (Ole) complexed with $0.5 \%$ fatty acid-free BSA in $0.1 \%$ FBSsupplemented media for $30 \mathrm{~min}$. The same media with no fatty acids was used as a control (BSA). Cellular levels of both phosphorylated and total Akt was determined by Western blotting. Bands were detected with a ChemiDoc (Bio-Rad) and quantified by densitometry. Data represent mean \pm SD of triplicate samples. ${ }^{*} \mathrm{P}<0.05$ vs. control cell line under the same treatment; $\dagger \mathrm{p}<0.05$ vs. BSA-treated control cells; \#p<0.05 vs. palmitic acid-treated control cells. One Way ANOVA and Bonferroni t-test.

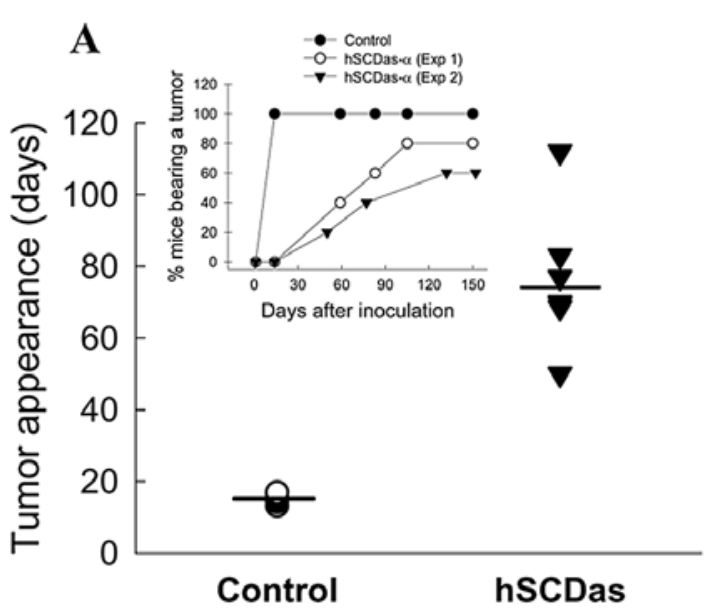

B

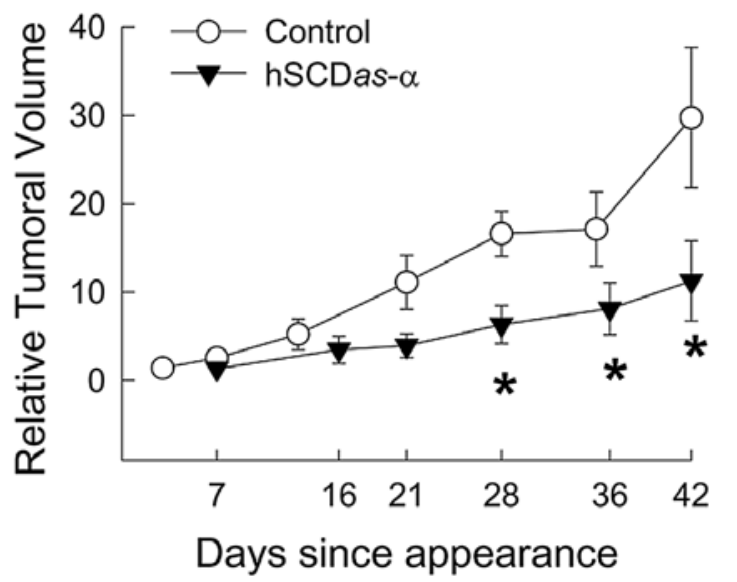

Figure 6. Delayed tumor appearance and reduced rate of tumor growth in SCD1-ablated A549 lung adenocarcinoma cells. Five mice received subcutaneous inoculations containing $1 \times 10^{6}$ A549 cells either bearing SCD1 gene knockdown or mock-transfected controls. Tumor appearance and growth was evaluated for up to 150 days. (A) Percentage of mice bearing detectable tumors in two experiments. (B) Rate of tumor growth. Data correspond to the mean $\pm \mathrm{SD}$ of four mice inoculated with hSCD1as- $\alpha$ cells and five mice injected with control cells. ${ }^{*} \mathrm{P}<0.05$, by ANOVA. of new tumors. Also noteworthy, SCD1-deficient cells were not able to develop into tumor formations in all mice injected with these cells. At the end of the experiments, after 150 days of inoculation with cancer cells, $20 \%$ (experiment 1 ) and $40 \%$ (experiment 2) of mice exhibited no measurable tumor masses (Fig. 6A, inset). Additionally, we determined whether A549 cells with the knockdown in SCD1 expression would develop tumors at a similar rate of control A549 cells. We compared the rate of tumor growth after initial tumor appearance and observed that tumor development was significantly reduced in mice inoculated with SCD1-ablated cells with respect to control cell-derived tumors (Fig. 6B), further indicating that SCD1 is required for sustaining tumor growth. Taken as a whole, these results strongly suggest a relevant role for SCD1 in early stages of tumor formation as well as in sustaining the rate of tumor growth.

\section{Discussion}

In the present study, we investigated whether the inhibition of SCD1 would modify the balance of MUFA/SFA in tumorforming A549 human lung adenocarcinoma cells, thereby altering the production of lipid structures and the activation of transduction signals that modulate cell lipid synthesis, with a consequent impact on in vivo tumor formation. We have previously shown that SCD1 plays a significant role in the regulation of lipid synthesis, the rate of cell proliferation and survival and in vitro invasiveness in human transformed cells $(4,20)$. Our observations that loss of SCD1 expression led to a significant reduction in the cellular content of MUFA in parallel with the increase in SFA levels, provide persuasive evidence of the relevance of SCD1 as the key regulator of fatty acid distribution in cancer cells $(4,20,32)$. Since neoplastic cells show an enrichment of phospholipids with MUFA that leads to highly fluid cell membranes $(4,8)$, the activation of SCD1 expression may be part of a mechanism that preserves a lipid membrane environment that would be more favorable for growth factor-mediated proliferation $(33,34)$ as well as for cancer growth and invasiveness (35-37). 


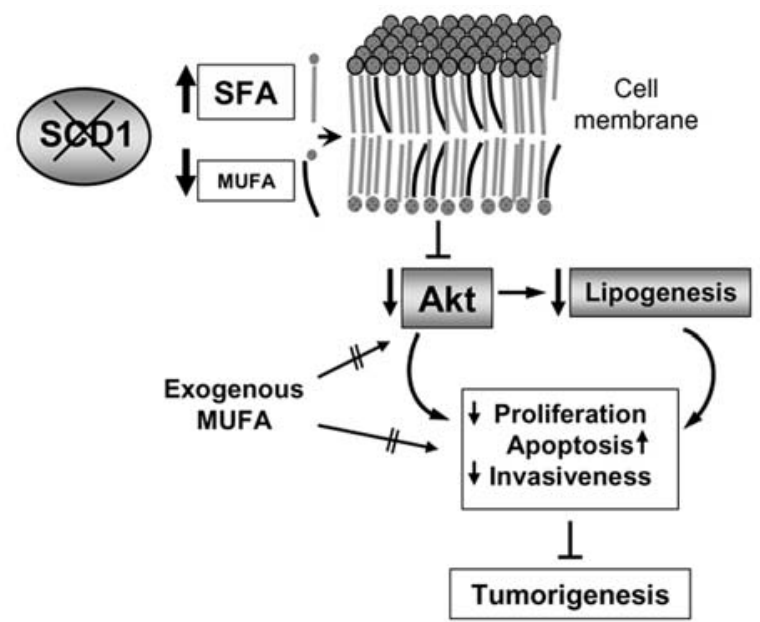

Figure 7. Hypothetical mechanism of the regulation of Akt signaling, lipid synthesis and tumorigenesis by SCD1 in A549 lung cancer cells. Stable inhibition of SCD1 expression promotes the downregulation of Akt activation and lipogenesis in A549 cells. This metabolic and signaling dysregulation in SCD1-ablated cells leads to lower rates of cell proliferation, invasiveness and tumor formation and growth. Exogenous MUFA are unable to reverse the biological changes promoted by SCD1 blockade in the cancer cells.

It has been proposed that SCD1 is a crucial factor in the regulation of cell proliferation, programmed cell death and fatty acid-mediated lipotoxicity $(20,26,38)$. SCD1 expression is triggered by growth factors in normal human cells (39-41) and is also a critical player in neoplastic cell growth (20). Our observation of a notable reduction in the rate of proliferation of SCD1-ablated cells unequivocally shows that SCD1 is a main factor in the control of cancer cell growth. Furthermore, SCD1 activity is required for the proliferative effects of exogenous MUFA since exogenous oleate stimulated proliferation in control A549 cancer cells, an effect previously reported for breast cancer cells (25), whereas oleate was ineffective in reversing the decrease in cell proliferation of SCD1-deficient cancer cells. In addition, the finding of a greater rate of apoptosis in SCD1-deficient A549 cells confirms previous observations in SV40-transformed cells and in lung and colon cancer cells in which ablation of SCD1 triggered programmed cell death $(20,42)$. Interestingly, the activation of SCD1 in A549 cells appears to be part of a safeguard mechanism to confront the toxic effects of excess endogenous and exogenous SFA. This hypothesis is supported by the finding that a greater rate of programmed cell death occurred when hSCDas- $\alpha$ cells were cultured in medium with sufficient oleic acid. Overload of SFA promotes metabolic conditions that trigger apoptosis in mammalian and human cells (43), hence the antiapoptotic effect of SCD1 may be likely caused by the conversion of toxic excess SFA into more harmless MUFA by the desaturase $(26,38)$. We have previously shown that, because of their constitutively high SCD1 expression levels, human oncogenetransformed cells convert most of both exogenous and de novo synthesized SFA into MUFA (4). More to this point, we observed that when SCD1 expression was reduced in these cells, the consequent increase in SFA content was accompanied by a greater rate of apoptosis (20).

Anchorage-independent growth, a hallmark of malignant transformation, was also found significantly decreased in
A549 cells with ablated expression of SCD1, further confirming that the synthesis of MUFA is essential for cancer cell invasiveness. However, unlike SCD1-ablated SV40-transformed cells (20), A549 cells with a chronic reduction SCD1 did not exhibit a total suppression of anchorage-independent cell proliferation. This discrepancy may lie in the fact that hSCDas- $\alpha$ cells showed $\sim 20 \%$ decrease in SCD activity compared to $\sim 70 \%$ reduction in the enzyme activity in SV40-cells with ablated SCD1 expression, suggesting that the alteration of the neoplastic cellular phenotype may be dependent on the degree of SCD1 inhibition.

Endogenously produced MUFA seem to be vital not only for cell growth but also for cancer cell invasiveness, since the alterations in proliferation and colony formation promoted by SCD1 ablation in A549 cells could not be overcome by supplying abundant MUFA ( $200 \mu \mathrm{M}$ oleate) in the cell culture medium. This result is in agreement with the observation in SCD1 knock out mice in which the alterations in lipid metabolism, particularly the synthesis of neutral lipids, could not be fully reversed by excess dietary MUFA $(44,45)$. The reason for the divergent effects of endogenous and exogenous oleic acid on cell metabolism is unknown. It has been speculated that exogenous and endogenous MUFA enter separated metabolic compartments and, hence, display different intracellular regulatory roles (46). However, the presence of a mechanism for such putative fatty acid segregation awaits experimental confirmation.

Alterations in MUFA and SFA content have been associated with cancer onset and progression. Studies performed in humans show that unbalanced levels of stearic acid (low) and oleic acid (high) appear positively correlated to cancer and metastasis, although it is not known if altered SCD1 activity alone is the cause of this imbalance (47-49). Furthermore, SCD1 expression has been linked with critical events of cancer development in several previous studies in cell culture and animal models. For example, the expression of SCD1 is increased by agents that predispose to carcinogenesis, including dichloroacetic acid (15) and peroxisome proliferators (46). Moreover, it was shown in mice and rats that the background level of SCD1 expression correlates with predisposition to liver carcinogenesis; the animals with the higher levels of SCD1 were more susceptible to chemical induction of cancer than those with lower SCD1 (50). In the present study, we demonstrated for the first time the direct participation of SCD1 in in vivo carcinogenesis. Stable ablation of SCD1 expression in A549 cells resulted in a clear delay in tumor formation in nude mice as well as in a more reduced rate of tumor growth. As these cells were still able to make large tumors, albeit fewer and more slowly, it is likely that other factors involved in tumorigenesis and cancer growth are unaffected by the lack of SCD1 expression. However, since the reduction in SCD1 expression levels was significant but moderate, a more pronounced inhibition of MUFA synthesis may be able to fully suppress tumor growth. Additionally, the anticancer effect of SCD1 inhibition has also been addressed by pharmacological inhibition of SCD enzyme activity. Sterculic acid, a cyclopropene fatty acid with inhibitory effects on SCD activity, has been shown to display antitumoral effects in vitro and in a tumor model in rats $(51,52)$ although the 
specificity of this effect is uncertain because this compound also inactivates other desaturases (53).

Several potential mechanisms can be postulated to explain the metabolic and phenotypical changes observed in SCD1ablated lung cancer cells that may ultimately lead to impaired tumor formation. A possible target for the effects of SCD1 deficiency is the signaling network, particularly the PI3K/Akt pathway, a central signaling pathway of clear relevance in carcinogenesis that controls numerous cellular functions, including cellular proliferation, growth, survival and mobility (54). Components of this signaling mechanism are commonly deregulated in cancer, including lung and breast cancer $(28,54)$. The regulatory role of endogenously synthesized MUFA synthesis on Akt signaling is little known. It has been reported that phosphorylation of Akt is upregulated in muscle of SCD $1^{-/}$mice (55), whereas siRNA-mediated ablation of SCD1 expression in rat muscle cells inhibited Akt phosphorylation on Ser473 (56). In the present study, we observed that the reduction of SCD1 expression in both A549 adenocarcinoma cells and in SV40-transformed human lung fibroblasts led to a significant decrease in Akt phosphorylation. Consistent with the impaired Akt activity, SCD1-ablated cells showed a decrease in phosphorylated GSK-3ß. Interestingly, Akt signaling is differentially modulated by exogenous SFA and MUFA. Incubation with oleic acid upregulates the activity of the Akt pathway in breast cancer cells and in muscle cells $(25,29,57)$. In contrast, exogenously added palmitic acid inhibits Akt activation by increasing PTEN or protein phosphatase 2A-like activity in endothelial and muscle cells $(58,59)$. In agreement with the aforementioned study in breast cancer cells, exogenous oleic acid induced Akt phosphorylation in mock-transfected A549 lung cancer cells. However, our observation that, oleic acid was unable to reverse the low Akt phosphorylation status in SCD1-deficient cells suggests that active synthesis of MUFA is required for the fatty acid-mediated activation of Akt signaling.

The alterations in glucose-derived lipid synthesis observed in SCD1-ablated cancer cells may be attributed to the inactivation of Akt since this signaling pathway plays a central role in the regulation of the associated processes of glycolysis and de novo lipid synthesis in cancer cells (24). In this connection, it has been observed that the induction of lipogenesis in human non-transformed and cancer cells by growth factors requires SREBP-1 activation through the stimulation of Akt signaling cascade $(6,40,41,60)$. SCD1 blockade may also alter cancer cell lipogenesis by affecting crucial regulators of glycolytic flow, such as phosphofructokinase- 1 and pyruvate kinase, as well as key enzymes in de novo synthesis of lipids such as ATP citrate lyase, acetyl CoA carboxylase and FAS, all of which are highly activated in cancer cells $(5,28,61)$. Adding to this hypothesis, alterations in the levels of glycolytic metabolites as well as the de novo synthesis of lipids in liver of $\mathrm{SCD}^{-/}$mice have been reported (62).

The observed downregulation of Akt signaling in SCD1ablated cancer cells may also explain the reversion in the cellular neoplastic phenotype since a decrease in cell proliferation, higher rates of apoptosis and reduced invasiveness were detected in A549 cells after inhibition of the Akt signaling pathway $(63,64)$. In addition, it has been reported that pharmacological inhibition of mTOR, a downstream effector of Akt, reduces tumor formation and progression in several in vivo tumor models $(65,66)$. At present, the molecular mechanisms by which SCD1 modulates Akt-mediated signaling mechanisms are not fully understood. It can be speculated that in cancer cells, by changing the ration MUFA/SFA in plasma membranes, SCD1 exercises a modulatory influence on tyrosine kinase receptors and other Akt-regulating signaling proteins that reside in the cell membrane or interact with membrane lipids. Nevertheless, experimental evidence supporting this hypothetical participation of SCD1 in a concerted regulation of lipid biosynthesis and Akt-mediated signaling transduction is lacking.

In summary, based on the results presented here we postulate that the specific inhibition of SCD1 activity in cancer cells decreases the ratio MUFA/SFA in cell membrane lipids, leading to inactivation of Akt signaling and impaired lipogenesis (Fig. 7). These metabolic and signaling effects of SCD1 blockade may promote the profound effects on cell proliferation, programmed cell death and invasiveness and, concomitantly, in the rates of tumor formation and tumor growth observed in SCD1-deficient lung cancer cells. The observation that exogenous MUFA cannot reverse the biochemical and biological perturbations of SCD1 ablation further underscores the relevant regulatory role of SCD1 in cancer cell biology.

In conclusion, this is the first direct demonstration that crucial features of malignant transformation, both in cultured cancer cells and in tumor xenografts, are determined by the level of SCD1 expression. These observations may shed new light on the role of MUFA synthesis and fatty acid composition of lipids in the control of cancer cell growth and tumor formation and lay the groundwork to develop new strategies of cancer therapy based on targeting SCD1 function.

\section{Acknowledgements}

We thank Dr Jean-Baptiste Demoulin for the anti-SCD1 antibody, Dr Wendie Cohick, Rutgers University for reagents and Dr Margarita Garcia-Bravo and Marisa Prinzo-Santangelo, University of la Plata School of Medicine for assistance with tumor experiments. We are indebted to Dr Judith Storch, Department of Nutritional Sciences, Rutgers University for her critical review of the manuscript. This study was supported by grants from Fundacion Antorchas, Argentina and Cook College/NJAES, Rutgers University. NS was supported by a fellowship from CONICET, Argentina.

\section{References}

1. Travis WD: Pathology of lung cancer. Clin Chest Med 23: 65-81, 2002.

2. Hatzivassiliou G, Zhao F, Bauer DE, Andreadis C, Shaw AN, Dhanak D, Hingorani SR, Tuveson DA and Thompson CB: ATP citrate lyase inhibition can suppress tumor cell growth. Cancer Cell 8: 311-321, 2005.

3. Kuhajda FP: Fatty acid synthase and cancer: new application of an old pathway. Cancer Res 66: 5977-5980, 2006.

4. Scaglia N, Caviglia JM and Igal RA: High stearoyl-CoA desaturase protein and activity levels in simian virus 40 transformed-human lung fibroblasts. Biochim Biophys Acta 1687: 141-151, 2005. 
5. Kuhajda FP: Fatty acid synthesis: a potential selective target for antineoplastic therapy. Proc Natl Acad Sci USA 91: 6379-6383, 1994.

6. Yang YA, Morin PJ, Han WF, Chen T, Bornman DM, Gabrielson EW and Pizer ES: Regulation of fatty acid synthase expression in breast cancer by sterol regulatory element binding protein-1c. Exp Cell Res 282: 132-137, 2003.

7. Baron A, Migita T, Tang D and Loda M: Fatty acid synthase: a metabolic oncogene in prostate cancer? J Cell Biochem 91: 47-53, 2004.

8. Ruggieri S, Roblin R and Black PH: Lipids of whole cells and plasma membrane fractions from Balb/c3T3, SV3T3, and concanavalin A-selected revertant cells. J Lipid Res 20: 760-771, 1979.

9. Bougnoux P, Chajes V, Lanson M, Hacene K, Body G, Couet C and Le Floch O: Prognostic significance of tumor phosphatidylcholine stearic acid level in breast carcinoma. Breast Cancer Res Treat 20: 185-194, 1992.

10. Horie Y, Suzuki A, Kataoka E, Sasaki T, Hamada K, Sasaki J, Mizuno K, Hasegawa G, Kishimoto H, Iizuka M, Naito M, Enomoto K, Watanabe S, Mak TW and Nakano T: Hepatocytespecific Pten deficiency results in steatohepatitis and hepatocellular carcinomas. J Clin Invest 113: 1774-1783, 2004.

11. Enoch HG, Catalá A and Strittmatter P: Mechanism of rat liver microsomal stearyl-CoA desaturase. Studies of the substrate specificity, enzyme-substrate interactions, and the function of lipid. J Biol Chem 251: 5095-5103, 1976.

12. Kumar-Sinha C, Ignatoski KW, Lippman ME, Ethier SP and Chinnaiyan AM: Transcriptome analysis of HER2 reveals a molecular connection to fatty acid synthesis. Cancer Res 63: 132-139, 2003.

13. Li J, Ding SF, Habib NA, Fermor BF, Wood CB and Gilmour RS: Partial characterization of a cDNA for human stearoyl-CoA desaturase and changes in its mRNA expression in some normal and malignant tissues. Int J Cancer 57: 348-352, 1994.

14. Lu J, Pei H, Kaeck M and Thompson HJ: Gene expression changes associated with chemically induced rat mammary carcinogenesis. Mol Carcinog 20: 204-215, 1997.

15. Thai SF, Allen JW, DeAngelo AB, George MH and Fuscoe JC: Detection of early gene expression changes by differential display in the livers of mice exposed to dichloroacetic acid. Carcinogenesis 22: 1317-1322, 2001.

16. Horton JD, Shah NA, Warrington JA, Anderson NN, Park SW, Brown MS and Goldstein JL: Combined analysis of oligonucleotide microarray data from transgenic and knockout mice identifies direct SREBP target genes. Proc Natl Acad Sci USA 100: 12027-12032, 2003.

17. Ettinger SL, Sobel R, Whitmore TG, Akbari M, Bradley DR, Gleave $\mathrm{ME}$ and Nelson $\mathrm{CC}$ : Dysregulation of sterol response element-binding proteins and downstream effectors in prostate cancer during progression to androgen independence. Cancer Res 64: 2212-2221, 2004.

18. Moore S, Knudsen B, True LD, Hawley S, Etzioni R, Wade C, Gifford D, Coleman I and Nelson PS: Loss of stearoyl-CoA desaturase expression is a frequent event in prostate carcinoma. Int J Cancer 114: 563-571, 2005.

19. Bagnato C and Igal RA: Overexpression of diacylglycerol acyltransferase- 1 reduces phospholipid synthesis, proliferation, and invasiveness in simian virus 40-transformed human lung fibroblasts. J Biol Chem 278: 52203-52211, 2003.

20. Scaglia N and Igal RA: Stearoyl-CoA desaturase is involved in the control of proliferation, anchorage-independent growth, and survival in human transformed cells. J Biol Chem 280: 25339-25349, 2005.

21. Bligh EG and Dyer WJ: A rapid method of total lipid extraction and purification. Can J Biochem Physiol 37: 911-917, 1959.

22. Wilson R and Sargent JR: Chain separation of monounsaturated fatty acid methyl esters by argentation thin-layer chromatography. J Chromatogr 905: 251-257, 2001.

23. Venable ME, Lee JY, Smyth MJ, Bielawska A and Obeid LM: Role of ceramide in cellular senescence. J Biol Chem 270: 30701-30708, 1995.

24. DeBerardinis RJ, Lum JJ, Hatzivassiliou G and Thompson CB: The biology of cancer: metabolic reprogramming fuels cell growth and proliferation. Cell Metab 7: 11-20, 2008.

25. Hardy S, St-Onge GG, Joly E, Langelier Y and Prentki M: Oleate promotes the proliferation of breast cancer cells via the $G$ protein-coupled receptor GPR40. J Biol Chem 280: 13285-13291, 2005.
26. Listenberger LL, Han X, Lewis SE, Cases S, et al: Triglyceride accumulation protects against fatty acid-induced lipotoxicity. Proc Natl Acad Sci USA 100: 3077-3082, 2003.

27. Elstrom RL, Bauer DE, Buzzai M, Karnauskas R, Harris MH, Plas DR, Zhuang H, Cinalli RM, Alavi A, Rudin CM and Thompson CB: Akt stimulates aerobic glycolysis in cancer cells. Cancer Res 64: 3892-3899, 2004.

28. Altomare DA and Testa JR: Perturbations of the AKT signaling pathway in human cancer. Oncogene 24: 7455-7464, 2005.

29. Hardy S, Langelier Y and Prentki M: Oleate activates phosphatidylinositol 3-kinase and promotes proliferation and reduces apoptosis of MDA-MB-231 breast cancer cells, whereas palmitate has opposite effects. Cancer Res 60: 6353-6358, 2000.

30. Cross DA, Alessi DR, Cohen P, Andjelkovich M and Hemmings BA: Inhibition of glycogen synthase kinase- 3 by insulin mediated by protein kinase B. Nature 378: 785-789, 1995 .

31. Grimes CA and Jope RS: The multifaceted roles of glycogen synthase kinase 3beta in cellular signaling. Prog Neurobiol 65: 391-426, 2001.

32. Choi Y, Park Y, Storkson JM, Pariza MW and Ntambi JM: Inhibition of stearoyl-CoA desaturase activity by the cis- 9 ,trans11 isomer and the trans-10,cis-12 isomer of conjugated linoleic acid in MDA-MB-231 and MCF-7 human breast cancer cells. Biochem Biophys Res Commun 294: 785-790, 2002.

33. Vacaresse N, Lajoie-Mazenc I, Auge N, Suc I, Frisach MF, Salvayre R and Negre-Salvayre A: Activation of epithelial growth factor receptor pathway by unsaturated fatty acids. Circ Res 85 : 892-899, 1999.

34. Ge G, Wu J and Lin Q: Effect of membrane fluidity on tyrosine kinase activity of reconstituted epidermal grow th factor receptor. Biochem Biophys Res Commun 282: 511-514, 2001.

35. Sok M, Sentjurc M and Schara M: Membrane fluidity characteristics of human lung cancer. Cancer Lett 139: 215-220, 1999.

36. Sok, M, Sentjurc M, Schara M, Stare J and Rott T: Cell membrane fluidity and prognosis of lung cancer. Ann Thorac Surg 73: 1567-1571, 2002.

37. McDonnel AC, Van Kirk EA, Isaak DD and Murdoch WJ: Inhibitory effects of progesterone on plasma membrane fluidity and tumorigenic potential of ovarian epithelial cancer cells. Exp Biol Med 228: 308-314, 2003.

38. Busch AK, Gurisik E, Cordery DV, Sudlow M, Denyer GS, Laybutt DR, Hughes WE and Biden TJ: Increased fatty acid desaturation and enhanced expression of stearoyl coenzyme A desaturase protects pancreatic beta-cells from lipoapoptosis. Diabetes 54: 2917-2924, 2005.

39. Samuel W, Nagineni CN, Kutty RK, Parks WT, Gordon JS, Prouty SM, Hooks JJ and Wiggert B: Transforming growth factor-beta regulates stearoyl coenzyme A desaturase expression through a Smad signaling pathway. J Biol Chem 277: 59-66, 2002.

40. Chang Y, Wang J, Lu X, Thewke DP and Mason RJ: KGF induces lipogenic genes through a PI3K and JNK/SREBP-1 pathway in H292 cells. J Lipid Res 46: 2624-2635, 2005.

41. Demoulin JB, Ericsson J, Kallin A, Rorsman C, Ronnstrand L and Heldin CH: Platelet-derived growth factor stimulates membrane lipid synthesis through activation of phosphatidylinositol 3-kinase and sterol regulatory element-binding proteins. J Biol Chem 279: 35392-35402, 2004.

42. Morgan-Lappe SE, Tucker LA, Huang X, Zhang Q, Sarthy AV, Zakula D, Vernetti L, Schurdak M, Wang J and Fesik SW: Identification of Ras-related nuclear protein, targeting protein for xenopus kinesin-like protein 2, and stearoyl-CoA desaturase 1 as promising cancer targets from an RNAi-based screen. Cancer Res 67: 4390-4398, 2007.

43. Schaffer JE: Lipotoxicity: when tissues overeat. Curr Opin Lipidol 14: 281-287, 2003.

44. Miyazaki M, Kim YC and Ntambi JM: A lipogenic diet in mice with a disruption of the stearoyl-CoA desaturase 1 gene reveals a stringent requirement of endogenous monounsaturated fatty acids for triglyceride synthesis. J Lipid Res 42: 1018-1024, 2001.

45. Sampath H, Miyazaki M, Dobrzyn A and Ntambi JM: Stearoyl CoA desaturase-1 mediates the pro-lipogenic effects of dietary saturated fat. J Biol Chem 282: 2483-2493, 2007.

46. Miller CW and Ntambi JM: Peroxisome proliferators induce mouse liver stearoyl-CoA desaturase 1 gene expression. Proc Natl Acad Sci USA 93: 9443-9448, 1996.

47. Bougnoux P, Giraudeau B and Couet C: Diet, cancer, and the lipidome. Cancer Epidemiol Biomarkers Prev 15: 416-421, 2006. 
48. Zureik M, Ducimetiere P, Warnet JM and Orssaud G: Fatty acid proportions in cholesterol esters and risk of premature death from cancer in middle aged French men. BMJ 311: 1251-1254, 1995.

49. Petrek JA, Hudgins LC, Ho M, Bajorunas DR and Hirsch JJ: Fatty acid composition of adipose tissue, an indication of dietary fatty acids, and breast cancer prognosis. Clin Oncol 15: 1377-1384, 1997.

50. Falvella FS, Pascale RM, Gariboldi M, et al: Stearoyl-CoA desaturase 1 (Scd1) gene overexpression is associated with genetic predisposition to hepatocarcinogenesis in mice and rats. Carcinogenesis 23: 1933-1936, 2002.

51. Fermor BF, Masters JR, Wood CB, Miller J, Apostolov K and Habib NA: Fatty acid composition of normal and malignant cells and cytotoxicity of stearic, oleic and sterculic acids in vitro. Eur J Cancer 28: 1143-1147, 1992.

52. Khoo DE, Fermor B, Miller J, Wood CB, Apostolov K, Barker W, Williamson RC and Habib NA: Manipulation of body fat composition with sterculic acid can inhibit mammary carcinomas in vivo. Br J Cancer 63: 97-101, 1991.

53. Cao J, Blond JP and Bezard J: Inhibition of fatty acid delta 6- and delta 5-desaturation by cyclopropene fatty acids in rat liver microsomes. Biochim Biophys Acta 1210: 27-34, 1993.

54. Vivanco I and Sawyers CL: The phosphatidylinositol 3-Kinase AKT pathway in human cancer. Nat Rev Cancer 2: 489-501, 2002.

55. Rahman SM, Dobrzyn A, Lee SH, Dobrzyn P, Miyazaki M and Ntambi JM: Stearoyl-CoA desaturase 1 deficiency increases insulin signaling and glycogen accumulation in brown adipose tissue. Am J Physiol Endocrinol Metab 288: 381-387, 2005.

56. Pinnamaneni SK, Southgate RJ, Febbraio MA and Watt MJ: Stearoyl CoA desaturase 1 is elevated in obesity but protects against fatty acid-induced skeletal muscle insulin resistance in vitro. Diabetologia 49: 3027-3037, 2006.

57. Yun MR, Lee JY, Park HS, Heo HJ, Park JY, Bae SS, Hong KW, Sung SM and Kim CD: Oleic acid enhances vascular smooth muscle cell proliferation via phosphatidylinositol 3-kinase/Akt signaling pathway. Pharmacol Res 54: 97-102, 2006.

58. Cazzolli R, Carpenter L, Biden TJ and Schmitz-Peiffer C: A role for protein phosphatase $2 \mathrm{~A}$-like activity, but not atypical protein kinase Czeta, in the inhibition of protein kinase B/Akt and glycogen synthesis by palmitate. Diabetes 50: 2210-2218, 2001 .
59. Wang XL, Zhang L, Youker K, Zhang MX, Wang J, LeMaire SA, Coselli JS and Shen YH: Free fatty acids inhibit insulin signaling-stimulated endothelial nitric oxide synthase activation through upregulating PTEN or inhibiting Akt kinase. Diabetes 55: 2301-2310, 2006 .

60. Porstmann T, Griffiths B, Chung YL, Delpuech O, Griffiths JR, Downward J and Schulze A: PKB/Akt induces transcription of enzymes involved in cholesterol and fatty acid biosynthesis via activation of SREBP. Oncogene 24: 6465-6481, 2005.

61. Chajès V, Cambot M, Moreau K, Lenoir GM and Joulin V: Acetyl-CoA carboxylase alpha is essential to breast cancer cell survival. Cancer Res 66: 5287-5294, 2006.

62. Miyazaki M, Flowers MT, Sampath H, Chu K, Otzelberger C, Liu X and Ntambi JM: Hepatic stearoyl-CoA desaturase-1 deficiency protects mice from carbohydrate-induced adiposity and hepatic steatosis. Cell Metab 6: 484-496, 2007.

63. Dasmahapatra GP, Didolkar P, Alley MC, Ghosh S, Sausville EA and Roy KK: In vitro combination treatment with perifosine and UCN-01 demonstrates synergism against prostate (PC-3) and lung (A549) epithelial adenocarcinoma cell lines. Clin Cancer Res 10: 5242-5252, 2004.

64. Sithanandam G, Fornwald LW, Fields J and Anderson LM: Inactivation of ErbB3 by siRNA promotes apoptosis and attenuates growth and invasiveness of human lung adenocarcinoma cell line A549. Oncogene 24: 1847-1859, 2005.

65. Majumder PK, Febbo PG, Bikoff R, Berger R, Xue Q, McMahon LM, Manola J, Brugarolas J, McDonnell TJ, Golub TR, Loda M, Lane HA and Sellers WR: mTOR inhibition reverses Akt-dependent prostate intraepithelial neoplasia through regulation of apoptotic and HIF-1-dependent pathways. Nat Med 10: 594-601, 2004.

66. Rossi F, Ehlers I, Agosti V, Socci ND, Viale A, Sommer G, Yozgat Y, Manova K, Antonescu CR and Besmer P: Oncogenic Kit signaling and therapeutic intervention in a mouse model of gastrointestinal stromal tumor. Proc Natl Acad Sci USA 103: 12843-12848, 2006 